\title{
PENGARUH KEADILAN ORGANISASIONAL DAN PEMBERDAYAAN PSIKOLOGIS TERHADAP COUNTERPRODUCTIVE WORK BEHAVIOR KARYAWAN PADA HOTEL MERCURE SANUR
}

\author{
Kadek Krisna Permana Putra ${ }^{1}$ \\ Putu Saroyeni Piartrini ${ }^{2}$
}

\author{
${ }^{1,2}$ Fakultas Ekonomi dan Bisnis Universitas Udayana (Unud), Bali, Indonesia \\ email: krisna.permana21@gmail.com
}

\begin{abstract}
ABSTRAK
Penelitian ini bertujuan untuk menganalisis pengaruh dari keadilan organisasional dan pemberdayaan psikologis terhadap counterproductive work behavior karyawan di Hotel Mercure Sanur, Bali. Landasan teori yang dipergunakan dalam penelitian ini adalah Social Exchange Theory, karena teori ini dapat memaparkan hubungan antara organizational citizenship behavior dan counterproductive work behavior serta pengaruh keadilan organisasional, kepuasan kerja, komitmen organisasional, dan pemberdayaan psikologis. Populasi dalam penelitian ini adalah 152 orang karyawan tetap di Hotel Mercure Sanur. Sampel yang digunakan dalam penelitian ini adalah 110 orang karyawan di Hotel Mercure Sanur, yang memiliki 5 kriteria sebagai berikut: umur, jenis kelamin, pendidikan terakhir, masa kerja dan jabatan pekerjaan. Penelitian ini hanya menggunakan rumus slovin sebagai formula didalam menentukan jumlah sampel yang akan dipergunakan, dikarenakan terbatasnya waktu untuk bertemu jadi hanya siapa yang bisa itu yang mengisi. Teknik analisis yang digunakan adalah Analisis regresi liniear berganda. Hasil analisis menunjukan bahwa keadilan organisasional dan pemberdayaan psikologi berpengaruh positif dan signifikan terhadap counterproductive work behavior karyawan di Hotel Mercure Sanur.
\end{abstract}

Kata kunci: keadilan organisasional, pemberdayaan psikologis, counterproductive work behavior

\begin{abstract}
This research purpose to analyze the influence of organizational justice and psychological empowerment on the counterproductive work behavior of employees at Mercure Hotel Sanur, Bali. The theoretical basis used in this research is the Social Exchange Theory, because this theory can explain the relationship between organizational citizenship behavior and counterproductive work behavior and the influence of organizational justice, job satisfaction, organizational commitment, and psychological empowerment. The population in this research were 152 permanent employees at Mercure Hotel Sanur. The sample used in this study was 110 employees at Mercure Sanur Hotel, which has 5 criteria as follows: age, gender, last education, years of service and job titles. This research only uses the Slovin formula as a formula in determining the number of samples to be used, due to the limited time to meet so only who can fill it. The analysis technique used is multiple linear regression analysis. The analysis showed that organizational justice and psychological empowerment had a positive and significant effect on the counterproductive work behavior of employees at Mercure Sanur Hotel.

Keywords: organizational justice, psychological empowerment, counterproductive work behavior
\end{abstract}




\section{PENDAHULUAN}

Hotel Mercure yang terletak di Sanur merupakan usaha akomodasi bintang 4 pertama yang dibangun oleh pihak Accor Hotels dan sekarang hotel ini telah dirubah menjadi sebuah Resort yang memiliki 189 kamar, serta memiliki sekitar 5 hektar taman tropis. Hotel Mercure Sanur memiliki 214 orang karyawan yang seluruhnya dibagi menjadi 2 jenis kontrak kerja, yakni karyawan yang memiliki kontrak kerja sebagai karyawan tetap berjumlah 152 orang dan karyawan yang memiliki kontrak kerja sebagai karyawan outsourcing berjumlah 62 orang. Studi awal dilakukan dengan mewawancarai karyawan yang memiliki jabatan supervisor di Hotel Mercure Sanur.

Hasil dari wawancara menunjukan bahwa banyak dari karyawan yang mengeluh tentang tuntutan kerja yang melebihi kapasitas dan merasa bekerja dibawah tekanan, karena dari pihak manajemen menuntut karyawan untuk siap melakukan pekerjaan secara profesional dan disiplin agar mampu memberikan kepuasan dan kenyamanan kepada customer. Keberhasilan dari suatu perusahaan tergantung pada bagaimana kinerja karyawan, efisiensi, kejujuran, ketekunan, dan integritas (Ahmed \& Uddin, 2012). Tuntutan pekerjaan serta aturan yang diterapkan kepada karyawan dapat memicu pressure tersendiri yang akan mempengaruhi produktifitas itu akan mengarah ke hal yang positif atau negatif.

Produktifitas merupakan tindakan yang dilakukan agar lebih baik dari apa yang dilakukan sebelumnya, serta mampu menunjukan peningkatan produktifitas kerja dengan lebih bijaksana dan bukan hanya sekedar kerja keras (Cascio, 2010). Produktifitas yang mengarah ke hal yang positif, karyawan akan memiliki perasaan tertantang untuk dapat meningkatkan pengalaman, menguatkan mental dan menjadi lebih paham dalam bagaimana seharusnya menyelesaikan setiap pekerjaan, namun apabila produktifitas mengarah ke hal yang negatif tentu karyawan yang berada di Hotel Mercure Sanur tersebut akan mengalami penurunan produktifitas, dan cenderung melakukan perilaku menyimpang seperti bekerja tidak maksimal, sengaja bekerja lebih lambat dari biasanya hingga melakukan cyberloafing. Perilaku kontraproduktif tidak selalu didominasi karyawan berusia muda, namun karyawan senior yang telah berusia dewasa madya bisa juga menjadi frustasi, tidak puas dan melakukan perilaku kontraproduktif (Permatasari, 2012).

Perilaku menyimpang karyawan tersebut dinamakan perilaku kerja kontraproduktif atau biasa disebut dengan counterproductive work behavior, yang dapat didefinisikan sebagai suatu perilaku atau tindakan yang disengaja dan bertentangan dengan norma-norma organisasi (Dalal, 2005). Counterproductive work behaviour dapat mengganggu organisasi melalui dampak langsung terhadap fungsi organisasi, atau menyakiti karyawan lain dengan maksud menurunkan produktifitas (Nugraheni \& Wahyuni, 2017). Counterproductive work behavior didefinisikan sebagai tindakan sukarela yang akan melanggar norma organisasi dan memiliki dampak negatif terhadap kesejahteraan karyawan dan organisasi (Robinson \& Bennett, 1995). Dimensi counterproductive work behavior yang dikembangkan oleh (M. L. Ambrose et al., 2002) menyebutkan bahwa terdapat empat tipe perilaku kerja dari sumber daya manusia yang bisa menurunkan kinerja perusahaan, diantaranya: penyimpangan produksi seperti memilih untuk pulang 
kerja lebih awal dan sengaja bekerja lebih lambat, penyimpangan terhadap harta benda perusahaan seperti mengambil barang milik perusahaan tanpa izin dan memalsukan tanda terima agar bisa mendapatkan lebih banyak uang, penyimpangan politik seperti menceritakan rahasia perusahaan dengan orang luar dan bergosip mengenai rekan kerja, dan agresi pribadi seperti mengabaikan perintah atasan dan menghina hasil kerja teman sejawat.

Hasil wawancara beserta kuesioner dari tiga orang karyawan di Hotel Mercure Sanur, ditemukan bahwa ada permasalahan yang berkaitan dengan counterproductive work behavior karyawan berupa sengaja bekerja lebih lambat dari kemampuan yang memiliki intensitas kejadian 4 kali dalam seminggu, membawa pulang barang atau makanan tanpa izin intensitas kejadian 1 kali dalam seminggu, membahas rahasia hotel atau keburukan hotel kepada orang luar intensitas kejadian hingga 3 kali dalam seminggu, mengabaikan atau menunda perintah atasan intensitas kejadiannya 1 kali dalam seminggu. Berdasarkan intensitasnya, bekerja lebih lambat dari kemampuan merupakan tindakan yang paling sering dilakukan. membahas rahasia hotel atau keburukan hotel kepada orang luar merupakan kejadian kedua yang cukup sering dilakukan oleh karyawan di Hotel Mercure Sanur, Bali. Padahal baik atau buruknya perusahaan ditentukan dari sumber daya manusianya, karena kualitas organisasi sendiri sangat tergantung pada kualitas dari sumber daya manusia sebagai karyawan dan pelaku layanan dalam suatu organisasi (Saltzstein et al., 2001).

Cukup seringnya intensitas kejadian mengenai counterproductive work behavior karyawan yang berada pada Hotel Mercure Sanur dapat dipengaruhi oleh rendahnya keadilan organisasional. Keadilan organisasional didefinisikan sebagai penilaian personal mengenai standar etika dan moral dari perilaku manajerial (Cropanzano et al., 2007). Keadilan organisasional adalah situasi yang digunakan untuk menggambarkan peran keadilan yang berkaitan langsung dengan tempat kerja dan apabila keadilan organisasional disuatu perusahaan itu rendah maka akan memicu timbulnya counterproductive work behavior (Al-Zu'bi, 2010).

Keadilan organisasional juga dapat diartikan sebagai suatu tingkat dimana seorang individu merasa diperlakukan sama di organisasi (Gibson et al., 2012). Hasil dari sejumlah studi menyatakan 70 persen organisasi atau perusahaan gagal melakukan perubahan dikarenakan adanya perilaku kontraproduktif dari anggota organisasi (Stephanus Josep, 2017). Berdasarkan wawancara dari beberapa karyawan di Hotel Mercure Sanur, ditemukan masalah yang berkaitan langsung dengan keadilan organisasional, yaitu adanya ketidak sesuaian imbalan yang diterima dengan kontribusi yang diberikan (keadilan distributif), perusahaan tidak menerapkan peraturan secara konsisten (keadilan prosedural), terkadang perlakuan atasan ke bawahan kurang sopan (keadilan interpersonal), terkadang atasan tidak menjelaskan aturan secara jujur dan menyeluruh (keadilan informasional). Hasil dari wawancara permasalahan tersebut, dapat dilihat bahwa adanya permasalahan mengenai rendahnya keadilan organisasional yang terjadi di Hotel Mercure Sanur. Keadilan organisasional memiliki empat jenis yang perlu diperhatikan, yakni keadilan distributif, keadilan prosedural, keadilan interpersonal, dan keadilan informasional (Colquitt et al., 2001). 
Beberapa karyawan menyatakan bahwa tingginya intensitas pressure didalam meningkatkan motivasi intrinsik sangat mempengaruhi psikis dan mental karyawan di Hotel Mercure Sanur, sehingga penelitian ini memutuskan memakai pemberdayaan psikologis sebagai variabel yang dapat mempengaruhi counterproductive work behavior. Pemberdayaan Psikologis merupakan suatu cara organisasi didalam meningkatkan motivasi intrinsik untuk seluruh karyawannya agar mampu mencapai tujuan yang diinginkan (Pfeffer et al., 1998). (Spreitzer, 1995) menyatakan bahwa terdapat empat dimensi dari pemberdayaan psikologis yang perlu diperhatikan, yakni. 1) Manfaat (Meaning) yang mengacu pada suatu alokasi hasil yang diterima oleh karyawan, 2) Kompetensi (Competence) yang mengacu pada suatu proses alokasi dalam pemberian tugas yang tepat dan dilakukan oleh organisasi kepada karyawan, 3) Penentuan Nasib Sendiri (Self-Determination) yang mengacu pada suatu tingkat kepercayaan pada diri sendiri yang dimiliki karyawan, 4) Pengaruh (Impact) yang mengacu pada suatu proses kerja yang tepat dan dilakukan oleh organisasi kepada karyawan. Berdasarkan wawancara dari 3 orang karyawan di Hotel Mercure Sanur, ditemukan permasalahan yang berkaitan dengan pemberdayaan psikologis, yakni terkadang karyawan merasa tugas yang diberikan dirasa kurang bermanfaat untuk meningkatkan kreatifitas karyawan (manfaat), terkadang karyawan merasa masih ada kesalahan didalam melakukan setiap pekerjaan yang diberikan (kompetensi), terkadang karyawan tidak memiliki banyak kesempatan didalam melakukan pekerjaan sesuai keinginannya (penentuan nasib sendiri), karyawan merasa tidak memiliki peran banyak atas kendali atas apa yang terjadi didepartemen nantinya (pengaruh). Organisasi perlu memandang karyawan sebagai pribadi yang mempunyai kebutuhan atas pengakuan dan penghargaan bukan sebagai alat untuk mencapai tujuan (Aris et al., 2017).

Penelitian sebelumnya yang membahas mengenai counterproductive work behavior dilakukan di Hotel Discovery Kartika Plaza Kuta dengan tujuan penelitian untuk mengetahui apakah keadilan organisasional dapat sebagai mediasi pengaruh kepemimpinan etis terhadap counterproductive work behaviour, sedangkan dalam penelitian ini dilakukan di Hotel Mercure Sanur dengan tujuan penelitian untuk mengetahui pengaruh keadilan organisasional dan pemberdayaan psikologis terhadap counterproductive work behavior. Secara rinci rumusan masalah dalam penelitian ini adalah sebagai berikut: bagaimanakah pengaruh keadilan organisasional terhadap counterproductive work behavior karyawan di Hotel Mercure Sanur, bagaimanakah pengaruh pemberdayaan psikologis terhadap counterproductive work behavior karyawan di Hotel Mercure Sanur. Manfaat dari penelitian ini diharapkan dapat digunakan sebagai masukan dan pertimbangan yang baik bagi manajerial di Hotel Mercure Sanur untuk dapat meminimalisasikan counterproductive work behavior yang terjadi pada karyawan, serta untuk kedepannya diharapkan mampu meningkatkan produktifitas seluruh karyawan yang berada di Hotel Mercure Sanur.

Konseptualisasi Keadilan Organisasional, Pemberdayan Psikologis, dan Counterproductive Work Behavior. Keadilan organisasional adalah persepsi keadilan seseorang terhadap keputusan yang diambil oleh manajerial (Colquitt $e t$ al., 2001). Keadilan organisasional diartikan sebagai suatu tingkat di mana 
seorang individu merasa diperlakukan sama di organisasi tempat dia bekerja (Gibson et al., 2012).

Keadilan organisasional memiliki empat dimensi, yaitu keadilan distributif, keadilan prosedural, keadilan interpersonal, dan keadilan informasional (Colquitt et al., 2001). Keadilan distributif ditandai sebagai keadilan terkait dengan distribusi sumber daya dan hasil keputusan (Usmani \& Jamal, 2013). keadilan imbalan yang didefinisikan sebagai penilaian yang dibuat orang terkait imbalan yang diterimanya dibanding imbalan yang diterima orang lain yang menjadi acuannya (Wiratama \& Rahyuda, 2017). Keadilan prosedural menurut (Robbins \& Judge, 2008), didefinisikan sebagai keadilan yang dirasakan dari proses yang digunakan untuk menentukan distribusi imbalan. (Wiratama \& Rahyuda, 2017) mendefinisikannya sebagai konsep keadilan yang berfokus pada metode yang digunakan untuk menentukan imbalan yang diterima. (Colquitt et al., 2001) melakukan meta-analisis danmenunjukkan bahwa keadilan distributif dan prosedural dapat dibedakan pengukurannya. (M. Ambrose \& Arnaud, 2005) menyatakan bahwa pengukuran terhadap keadilan distributif secara relatif konsisten pada seluruh penelitian. Keadilan interaksional menurut Robbins (2008:49), didefinisikan sebagai persepsi individu tentang tingkat sampai dimana seorang karyawan diperlakukan dengan penuh martabat, perhatian, dan rasa hormat. (Kristanto et al., 2014) menyatakan bahwa keadilan interaksional dihubungkan dengan evaluasi supervisor langsung sedangkan keadilan prosedural dihubungkan dengan evaluasi sistem organisasional, sehingga keduanya merupakan konstruk yang independen. Keadilan informasional didefinisikan sebagai persepsi individu tentang keadilan informasi yang digunakan sebagai dasar pembuatan keputusan (Robbins \& Judge, 2008). Keadilan informasional menekankan kepada akurasi dan kualitas penjelasan yang individu terima (Lewis, 2013). Keadilan organisasional adalah faktor efektif yang dapat mengurangi perilaku kontraproduktif (Appelbaum et al., 2005).

Hasil studi (Wiratama \& Rahyuda, 2017), menyatakan penyebab kecenderungan perilaku kontraproduktif terjadi karena adanya ketidakadilan di dalam organisasi. Keadilan organisasional ditemukan memiliki pengaruh yang signifikan terhadap perilaku kontraproduktif (Rafiee et al., 2015). (Ahmed \& Uddin, 2012) juga menemukan bahwa keadilan organisasional dapat meredam perilaku kontraproduktif karyawan. Penelitian lain yang dilakukan oleh (Wiratama \& Rahyuda, 2017) menunjukan bahwa keadilan organisasi berpengaruh positif signifikan terhadap counterproductive work behavior. Berdasarkan bukti empiris tersebut, maka dapat dirumuskan bahwa hipotesis penelitian sebagai berikut:

$\mathrm{H}_{1}$ : Keadilan organisasional berpengaruh positif signifikan terhadap counterproductive work behavior.

Pemberdayan Psikologis adalah manifestasi dari motivasi intrinsik yang tercermin pada orientasi individu dalam perannya di pekerjaan (Anindyajati \& Karima, 2004). Spreitzer (1995) menyatakan bahwa pemberdayaan psikologis memiliki 4 dimensi yakni: manfaat, indikator ini dapat diukur dari persepsi responden mengenai pekerjaan yang dilakukan akan mendapatkan penilaian hasil kinerja yang dilakukan oleh organisasi tempatnya bekerja. Kompetensi, indikator 
ini dapat diukur dari persepsi responden mengenai kompetensi yang dimiliki responden terhadap kemampuan dirinya dalam menerima tugas dan mampu menyelesaikan setiap pekerjaan yang di berikan atasan atau organisasi.

Menentukan nasib sendiri, indikator ini dapat diukur dari persepsi responden mengenai kepercayaan terhadap diri sendiri dalam mengambil keputusan serta mampu menyelesaikan setiap permasalahan di tempat bekerja. Pengaruh, indikator ini dapat diukur dari persepsi responden mengenai pengaruh yang dimiliki responden terhadap peranannya dalam melakukan suatu pekerjaan mampu berpengaruh terhadap departemen di organisasi. Pemberdayaan psikologis pada umumnya merupakan sebuah langkah awal dari perubahan yang baik untuk organisasi, namun (Pfeffer et al., 1998) berpendapat bahwa pemberdayaan psikologis memiliki dampak positif dan negatif terhadap counterproductive work behavior. Pemberdayaan psikologis menyebabkan seorang karyawan dapat terlalu percaya diri dan cenderung salah menilai karyawan lainnya, serta karyawan yang terlalu percaya diri juga cenderung akan mengarah pada counterproductive work behavior didalam mencapai tujuan organisasinya (Conger \& Kanungo, 1988).

Karyawan yang melakukan counterproductive wok behavior juga akan terlibat dalam hal-hal yang negatif, seperti suasana hatinya yang buruk dan kinerjanya yang berkurang (Wilkerson et al., 2008). Pemberdayaan psikologis karyawan di suatu perusahaan dapat berpengaruh positif terhadap counterproductive wok behavior (Aris et al., 2017). Pemberdayaan psikologi juga akan muncul ketika seorang karyawan merasa berhak atau superioritas, dan karyawan yang diberdayakan juga dapat mengimbangi kontribusi positif yang mereka dapat dengan yang negatif. (Luth, 2013) berpendapat bahwa meningkatkan motivasi intrinsik pada karyawan yang diberdayakan dapat memberi pengaruh yang positif serta dapat mengubah situasi untuk diri mereka sendiri atau organisasi, tergantung pada perubahan tersebut diperlukan atau tidak oleh organisasi, sedangkan apabila hasil dari perubahan tidak sesuai maka pengaruh dari pemberdayaan akan cenderung mengarah kepada counterproductive work behavior. Berdasarkan kajian penelitian tersebut, maka dapat dirumuskan bahwa hipotesis penelitian sebagai brikut:

$\mathrm{H}_{2}$ : Pemberdayaan psikologis berpengaruh positif signifikan terhadap counterproductive work behavior.

Desain penelitian yang digunakan dalam penelitian ini adalah survei, yang melibatkan karyawan tetap di Hotel Mercur Sanur. Obyek penelitian ini adalah keadilan organisasional, pemberdayaan psikologis, dan counterproductive work behavior karyawan di Hotel Mercure Sanur, Bali. Variabel yang diteliti dalam penelitian yakni: keadilan organisasional $\left(\mathrm{X}_{1}\right)$ adalah tindakan yang digunakan untuk menggambarkan peran keadilan yang sering terjadi di dalam organisasi (AlZu'bi, 2010), pemberdayaan psikologis $\left(\mathrm{X}_{2}\right)$ adalah pemberdayan psikologis adalah manifestasi dari motivasi intrinsik yang tercermin pada orientasi individu dalam perannya di pekerjaan (Harding, 2019) sebagai variabel bebas, dan counterproductive work behavior (Y) adalah tindakan ketidaksopanan, kekerasan, dan perilaku menyimpang yang dapat melanggar norma organisasi serta dapat mengancam kesejahteraan organisasi maupun kinerja karyawan (Reisel et al., 2010) sebagai variabel terikat. 


\section{METODE PENELITIAN}

Lokasi penelitian ini dilakukan di Hotel Mercure yang berada di wilayah Sanur-Bali. Hotel Mercure ini dipilih sebagai lokasi penelitian karena mudah dijangkau dan bersedia untuk melakukan penelitian dengan batasan hanya boleh menggunakan karyawan yang memiliki jabatan supervisor ke bawah sebagai responden, sedangkan untuk manager, executive, dan general manager tidak diperkenankan. Hipotesis penelitian ini adalah keadilan organisasional berpengaruh positif signifikan terhadap counterproductive work behavior, dan pemberdayaan psikologis berpengaruh positif signifikan terhadap counterproductive work behavior

Populasi dalam penelitian ini adalah 152 orang karyawan tetap di Hotel Mercure Sanur. Dalam menentukan jumlah sampel atau responden yang diinginkan, penelitian ini hanya menggunakan rumus slovin sebagai formula didalam menentukan jumlah sampel yang akan dipergunakan, dikarenakan terbatasnya waktu untuk bertemu jadi hanya siapa yang bisa itu yang mengisi. Jadi sampel yang digunakan dalam penelitian ini adalah 110 orang karyawan tetap di Hotel Mercure Sanur, yang berada di jabatan engineering supervisor 2 orang, front office supervisor 2 orang, house keeping supervisor 2 orang, sport \& recreation supervisor 2 orang, human resource supervisor 1 orang, restaurant supervisor 3 orang, steward supervisor 1 orang, enggenering 12 orang, front office 10 orang, , housekeeping 12 orang, sport \& recreation 8 orang, financial 7 orang, security 6 orang, sales 7 orang, kitchen 12 orang, steward 5 orang, dan food \& beverage service 18 orang.

Data penelitian ini dikumpulkan dari sumber primer dan sekunder. Data primer dalam penelitian ini antara lain adalah persepsi keadilan organisasional, persepsi pemberdayaan psikologis dan counterproductive work behavior. Data sekunder yang dikumpulkan adalah data jumlah karyawan, jenis jabatan, dan jenis perilaku kontraproduktif dari hasil penelitian sebelumnya, seperti: penelitian yang telah dilakukan oleh peneliti sebelumnya, artikel dan yang lainnya. Data kuantitatif adalah data yang berbentuk angka atau dinyatakan dalam satuan tertentu. Data kuantitatif yang digunakan dalam penelitian ini adalah jumlah karyawan Hotel Mercure Sanur yang melakukan counterproductive work behavior pada saat bekerja, usia karyawan, masa kerja. Data kualitatif adalah data yang tidak berbentuk angka atau dinyatakan dengan satuan ukuran tertentu. Data kualitatif yang digunakan didalam penelitian ini meliputi persepsi keadilan organisasional, persepsi pemberdayaan psikologis dan jenis perilaku counterproductive work behavior unit kerja responden karyawan di Hotel Mercure Sanur.

Metode pengumpulan data yang digunakan dalam penelitian ini adalah wawancara dan kuisioner. Metode wawancara dilakukan dengan cara tanya jawab langsung dengan karyawan tetap biasa dan karyawan yang memiliki jabatan supervisor. Pertanyaan yang diajukan seperti permasalahan mengenai keadilan oranisasional, pemberdayaan psikologis, dan counterproductive work behavior. Metode kuisioner, merupakan metode pengumpulan data dengan menggunakan daftar pertanyaan secara tertulis. Didesain dengan mengacu pada instrumen 
pengukuran data yang telah teruji den memiliki kredibilitas memadai seperti instrument keadilan oranisasional, pemberdayaan psikologi, dan counterproductive work behavior. Penilaian ini menggunakan skala likert.

Data variabel keadilan organisasional dapat diukur dengan instrumen penelitian milik (Rafiee et al., 2015) meliputi: keadilan distributif, keadilan prosedural, keadilan interaksional, keadilan informasional. Keadilan organisasional memiliki 19 butir pernyataan yakni, imbalan yang saya terima mencerminkan usaha yang diberikan dalam pekerjaan, imbalan yang saya terima sesuai dengan pekerjaan yang diselesaikan, imbalan yang saya terima mencerminkan kontribusi saya kepada perusahaan, imbalan yang saya terima sesuai dengan kinerja yang saya hasilkan, perusahaan memberikan kesempatan kepada saya untuk mengungkapkan pandangan selama peraturan diterapkan, perusahaan memberikan kesempatan kepada saya untuk ikut mengawasi penerapan peraturan, perusahaan menerapkan peraturan secara konsisten, tidak ada orang atau kelompok yang diistimewakan dalam penerapan peraturan, karyawan dapat mengajukan keberatan terkait penerapan peraturan perusahaan, peraturan-peraturan perusahaan menjunjung tinggi standar moral dan etika, atasan memperlakukan saya dengan cara yang sopan, atasan memperlakukan saya dengan penuh martabat, atasan memperlakukan saya dengan rasa hormat, atasan saya tidak berkata-kata atau berkomentar yang tidak pantas, atasan saya jujur dalam berkomunikasi, atasan menjelaskan peraturan/ prosedur secara menyeluruh, penjelasan yang diberikan kepada saya terkait peraturan/prosedur masuk akal, atasan berkomunikasi secara rinci kapanpun diperlukan, atasan menyesuaikan komunikasinya terhadap karyawan sesuai dengan porsinya. Data dari keadilan organisasional ini memiliki 19 butir pernyataan dan dapat diukur dengan skal likert dengan interval 1 sampai 5 yang mewakili interval sangat tidak setuju hingga sangat setuju.uji validitas instrumen pengukuran data dilakukan dengan parameter $\mathrm{r}$ minimal 0,3 dan uji reliabilitas dilakukan dengan metode skala berdasarkan parameter alpha cronbach minimal 0,60.

Data variabel pemberdayaan psikologis dapat diukur dengan instrumen penelitian milik (Spreitzer, 1995) yang meliputi: manfaat, kompetensi, menentukan nasib sendiri, pengaruh. Pemberdayaan psikologis memiliki 12 butir pernyataan yakni, pekerjaan yang saya lakukan sangat penting bagi saya, aktivitas pekerjaan saya secara pribadi sangat berarti bagi saya, pekerjaan yang saya lakukan itu sangat bermakna bagi saya, saya yakin dengan kemampuan saya untuk melakukan pekerjaan, saya yakin dengan kemampuan saya untuk dapat melakukan aktivitas kerja saya, saya telah menguasai keterampilan yang diperlukan untuk pekerjaan saya, saya memiliki cara tersendiri dalam menentukan bagaimana saya melakukan pekerjaan saya, saya dapat memutuskan sendiri cara mengerjakan pekerjaan saya, saya memiliki banyak kesempatan untuk kebebasan dan bebas dalam bagaimana saya melakukan pekerjaan saya, dampak saya pada apa yang terjadi di departemen saya sangat besar, saya memiliki banyak kontrol atas apa yang terjadi di departemen saya, saya memiliki pengaruh yang signifikan atas apa yang terjadi di departemen saya. Data dari pemberdayan psikologis ini memiliki 12 butir pernyataan dan dapat diukur dengan skal likert dengan interval 1 sampai 5 yang mewakili interval sangat tidak setuju hingga sangat setuju.uji 
validitas instrumen pengukuran data dilakukan dengan parameter $\mathrm{r}$ minimal 0,3 dan uji reliabilitas dilakukan dengan metode skala berdasarkan parameter alpha cronbach minimal 0,60.

Data variabel Counterproductive work behavior dapat diukur dengan instrumen penelitian milik (Brief \& Weiss, 2002) meliputi: penyimpangan produksi, penyimpangan property, penyimpangan politik, agresi pribadi. Counterproductive work behavior memiliki 13 butir pernyataan yakni, saya sering menghabiskan banyak waktu berfantasi atau melamun daripada bekerja, saya sering istirahat lebih lama, saya sering datang terlambat, saya sengaja bekerja lebih lambat dari kemampuan, sedikit usaha yang saya berikan saat bekerja, saya sering mengambil properti kantor tanpa izin, saya sering mengotori lingkungan kerja, saya sering memalsukan tanda terima untuk mendapatkan lebih banyak uang dari yang telah dikeluarkan semestinya, saya sering membahas rahasia perusahaan dengan orang yang tidak semestinya, saya sering bergosip, saya sering menggunakan obat atau alkohol saat bekerja, saya sering mengejek rekan kerja, saya sering mengabaikan instruksi atasan. Data dari counterproductive work behavior ini memiliki 13 butir pernyataan dan dapat diukur dengan skal likert dengan interval 1 sampai 5 yang mewakili interval sangat tidak setuju hingga sangat setuju.uji validitas instrumen pengukuran data dilakukan dengan parameter r minimal 0,3 dan uji reliabilitas dilakukan dengan metode skala berdasarkan parameter alpha cronbach minimal 0,60. data dari keadilan organisasional ini memiliki 13 butir pernyataan dan dapat diukur dengan skal likert dengan interval 1sampai 5 yang mewakili interval sangat tidak setuju hingga sangat setuju.uji validitas instrumen pengukuran data dilakukan dengan parameter $\mathrm{r}$ minimal 0,3 dan uji reliabilitas dilakukan dengan metode skala berdasarkan parameter alpha cronbach minimal 0,60 .

Uji hipotesis penelitian dilakukan dengan metode analisis regresi linier berganda. Analisis regresi linier berganda digunakan untuk meramalkan bagaimana keadaan (naik turunnya) variabel dependen (kriterium), bila dua atau lebih variabel independen sebagai faktor predictor dimanipulasi (dinaik turunkan nilainya) (Sugiyono, 2013). Jadi analisis regresi ganda akan dilakukan bila jumlah variabel independennya minimal dua.

\section{HASIL DAN PEMBAHASAN}

Berdasarkan data dari 110 responden yang merupakan karyawan di Hotel Mercure Sanur, dapat digambarkan karakteristik responden yang meliputi lima aspek yaitu: umur, jenis kelamin, pendidikan terakhir, masa kerja dan jabatan pekerjaan. Karakteristik responden memiliki kriteria umur dari 18-24 tahun berjumlah 14 orang responden yang memiliki persentase 12,7 persen, umur $25-34$ tahun berjumlah 30 orang responden dengan persentase 27,2 persen, umur 35-44 tahun berjumlah 28 orang responden dengan persentase 25,4 persen, 45-54 tahun berjumlah 34 orang responden dengan persentase 30,9 persen, dengan jumlah responden adalah 110 orang dengan persentase 100 persen. Jadi responden menurut umur menunjukkan bahwa responden berusia $45-54$ tahun 
mendominasi terhadap tempat kerja di Hotel Mercure Sanur, mengingat pada usia tersebut akan sangat rentan untuk melakukan counterproductive work behavior.

Responden memiliki kriteria jenis kelamin laki-laki berjumlah 72 orang responden dengan persentase 65,45 persen, sedangkan untuk jenis kelamin perempuan berjumlah 38 orang responden dengan persentase 34,54 persen., dengan jumlah total responden adalah 110 orang dengan persentase 100 persen. Jadi Responden menurut jenis kelamin menunjukkan bahwa karyawan laki-laki lebih mendominasi terhadap tempat kerja di Hotel Mercure Sanur.

Responden yang memiliki tingkat pendidikan terakhir dari SD berjumlah 8 orang responden yang memiliki persentase 7,2 persen, SMP berjumlah 13 orang responden dengan persentase 11,8 persen, SMA berjumlah 48 orang responden dengan persentase 48,6 persen, Diploma berjumlah 25 orang responden dengan persentase 22,7 persen. Sarjana berjumlah 11 orang responden dengan persentase 10 persen. Magister berjumlah 5 orang responden dengan persentase 4,5 persen, dengan jumlah responden adalah 110 orang dengan persentase 100 persen. Jadi

Responden menurut tingkat pendidikan terakhir sebagian besar karyawan yang bekerja di Hotel Mercure Sanur yang memiliki pendidikan SMA susah untuk mengikuti perkembangan teknologi di jaman ini. Responden yang memiliki masa kerja mulai dari 0-5 tahun berjumlah 32 orang responden yang memiliki persentase 29 persen, masa kerja 6-10 tahun berjumlah 26 orang responden dengan persentase 23,6 persen, masa kerja 11-20 tahun berjumlah 38 orang responden dengan persentase 34,5 persen, dan yang memiliki masa kerja lebih dari 20 tahun berjumlah 14 orang responden dengan persentase 12,7 persen, dengan jumlah responden adalah 110 orang dengan persentase 100 persen. Jadi sebagian besar responden yang memiliki masa kerja dari 11 tahun hingga 20 tahun, yaitu sebesar 34,5 persen ini rentan didalam melakukan counterproductive work behavior. Namun tidak dapat dipungkiri bahwa karyawan yang memiliki masa kerja lebih dari 20 tahun pasti merasa jenuh, yaitu sebesar 12,7 persen juga jauh lebih rentan didalam melakukan counterproductive work behavior.

Responden yang memiliki jabatan dari engineering supervior berjumlah 2 orang responden yang memiliki persentase 1,8 persen, front office supervior berjumlah 2 orang responden dengan persentase 1,8 persen, house keeping supervior berjumlah 2 orang responden dengan persentase 1,8 persen, sport \& recreation supervisor berjumlah 2 orang responden dengan persentase 1,8 persen. human resource supervisor berjumlah 1 orang responden dengan persentase 0,9 persen. restaurant supervisor berjumlah 3 orang responden dengan persentase 2,7 persen, steward supervisor berjumlah 1 orang responden dengan persentase 0,9 persen, engineering berjumlah 12 orang responden dengan persentase 10,9 persen, front office berjumlah 10 orang responden dengan persentase 9 persen, housekeeping berjumlah 12 orang responden dengan persentase 10,9 persen, sport \& recreation berjumlah 8 orang responden dengan persentase 7,2 persen, financial berjumlah 7 orang responden dengan persentase 6,3 persen, security berjumlah 6 orang responden dengan persentase 5,4 persen, sales berjumlah 7 orang responden dengan persentase 6,3 persen, kitchen berjumlah 12 orang responden dengan persentase 10,9 persen, steward berjumlah 5 orang responden dengan persentase 4,5 persen, food \& beverage serviceberjumlah 18 orang 
Kadek Krisna Permana Putra, Pengaruh Keadilan Organisasional...

responden dengan persentase 16,3 persen, dengan jumlah responden adalah 110 dengan persentase 100 persen. Jadi responden menurut jabatan karyawan yang memiliki jabatan lain, seperti Human resource supervisor dan Steward supervisor yaitu sebesar 0,9 persen juga akan rentan didalam melakukan counterproductive work behavior.

Instrumen penelitian dikatakan valid jika mampu mengukur apa yang seharusnya diukur, dan dapat mengungkap data dari variabel yang diteliti secara tepat. Syarat minimum untuk dianggap memenuhi syarat adalah kalua $r=0,3$. Jadi kalau korelasi antar butir skor dengan skor total lebih dari 0,3 maka butir dalam instrumen tersebut dinyatakan valid. Hasil uji validitas instrumen yakni, variabel keadilan organsiasinoal memiliki indikator imbalan yang saya terima mencerminkan usaha yang diberikan dalam pekerjaan memiliki korelasi 0,766 dengan keterangan valid, imbalan yang saya terima sesuai dengan pekerjaan yang diselesaikan memiliki korelasi 0,781 dengan keterangan valid, imbalan yang saya terima mencerminkan kontribusi saya kepada perusahaan memiliki korelasi 0,757 dengan keterangan valid, imbalan yang saya terima sesuai dengan kinerja yang saya hasilkan memiliki korelasi 0,693 dengan keterangan valid, perusahaan memberikan kesempatan kepada saya untuk mengungkapkan pandangan selama peraturan diterapkan memiliki korelasi 0,733 dengan keterangan valid, perusahaan memberikan kesempatan kepada saya untuk ikut mengawasi penerapan peraturan memiliki korelasi 0,763 dengan keterangan valid, perusahaan menerapkan peraturan secara konsisten memiliki korelasi 0,824 dengan keterangan valid, tidak ada orang atau kelompok yang diistimewakan dalam penerapan peraturan memiliki korelasi 0,659 dengan keterangan valid, karyawan dapat mengajukan keberatan terkait penerapan peraturan perusahaan memiliki korelasi 0,797 dengan keterangan valid, peraturan-peraturan perusahaan menjunjung tinggi standar moral dan etika memiliki korelasi 0,801 dengan keterangan valid, atasan memperlakukan saya dengan cara yang sopan memiliki korelasi 0,782 dengan keterangan valid, atasan memperlakukan saya dengan penuh martabat memiliki korelasi 0,843 dengan keterangan valid, atasan memperlakukan saya dengan rasa hormat memiliki korelasi 0,756 dengan keterangan valid, atasan saya tidak berkata-kata atau berkomentar yang tidak pantas memiliki korelasi 0,773 dengan keterangan valid, atasan saya jujur dalam berkomunikasi memiliki korelasi 0,788 dengan keterangan valid, atasan menjelaskan peraturan/ prosedur secara menyeluruh memiliki korelasi 0,828 dengan keterangan valid, penjelasan yang diberikan kepada saya terkait peraturan/prosedur masuk akal memiliki korelasi 0,829 dengan keterangan valid, atasan berkomunikasi secara rinci kapanpun diperlukan memiliki korelasi 0,814 dengan keterangan valid, atasan menyesuaikan komunikasinya terhadap karyawan sesuai dengan porsinya memiliki korelasi 0,829 dengan keterangan valid.

Variabel pemberdayaan psikologis memiliki indikator pekerjaan yang saya lakukan sangat penting bagi saya memiliki korelasi 0,779 dengan keterangan valid, aktivitas pekerjaan saya secara pribadi sangat berarti bagi saya memiliki korelasi 0,755 dengan keterangan valid, pekerjaan yang saya lakukan itu sangat bermakna bagi saya memiliki korelasi 0,909 dengan keterangan valid, saya yakin dengan kemampuan saya untuk melakukan pekerjaan memiliki korelasi 0,724 
dengan keterangan valid, saya yakin dengan kemampuan saya untuk dapat melakukan aktivitas kerja saya memiliki korelasi 0,815 dengan keterangan valid, saya telah menguasai keterampilan yang diperlukan untuk pekerjaan saya memiliki korelasi 0,715 dengan keterangan valid, saya memiliki cara tersendiri dalam menentukan bagaimana saya melakukan pekerjaan saya memiliki korelasi 0,732 dengan keterangan valid, saya dapat memutuskan sendiri cara mengerjakan pekerjaan saya memiliki korelasi 0,763 dengan keterangan valid, saya memiliki banyak kesempatan untuk kebebasan dan bebas dalam bagaimana saya melakukan pekerjaan saya memiliki korelasi 0,825 dengan keterangan valid, dampak saya pada apa yang terjadi di departemen saya sangat besar memiliki korelasi 0,769 dengan keterangan valid, saya memiliki banyak kontrol atas apa yang terjadi di departemen saya memiliki korelasi 0,856 dengan keterangan valid, saya memiliki pengaruh yang signifikan atas apa yang terjadi di departemen saya memiliki korelasi 0,757 dengan keterangan valid. Variabel counterproductive work behavior memiliki indikator saya sering menghabiskan banyak waktu berfantasi atau melamun daripada bekerja memiliki korelasi 0,886 dengan keterangan valid, saya sering istirahat lebih lama memiliki korelasi 0,942 dengan keterangan valid, saya sering datang terlambat memiliki korelasi 0,916 dengan keterangan valid, saya sengaja bekerja lebih lambat dari kemampuan memiliki korelasi 0,922 dengan keterangan valid, sedikit usaha yang saya berikan saat bekerja memiliki korelasi 0,929 dengan keterangan valid, saya sering mengambil properti kantor tanpa izin memiliki korelasi 0,933 dengan keterangan valid, saya sering mengotori lingkungan kerja memiliki korelasi 0,928 dengan keterangan valid, saya sering memalsukan tanda terima untuk mendapatkan lebih banyak uang dari yang telah dikeluarkan semestinya memiliki korelasi 0,904 dengan keterangan valid, saya sering membahas rahasia perusahaan dengan orang yang tidak semestinya memiliki korelasi 0,960 dengan keterangan valid, saya sering bergosip memiliki korelasi 0,919 dengan keterangan valid, saya sering menggunakan obat atau alkohol saat bekerja memiliki korelasi 0,948 dengan keterangan valid, saya sering mengejek rekan kerja memiliki korelasi 0,965 dengan keterangan valid, saya sering mengabaikan instruksi atasan memiliki korelasi 0,968 dengan keterangan valid. Jadi butir-butir pernyataan variabel keadilan organisasional, pemberdayaan psikologis dan counterproductive work behavior secara keseluruhan dalam penelitian ini adalah valid.

Reliabilitas merupakan suatu angka indeks yang menunjukan kosistensi suatu alat ukur dalam mengukur gejala yang sama. Uji reliabilitas mampu menunjukan sejauh mana instrument dapat dipercaya dan diharapkan. Nilai suatu instrument dikatakan reliable apabila nilai Alpha Cronbach 0,6. Hasil uji reliabilitas Keadilan Organisasional adalah 0,963 dengan keterangan reliabel, Pemberdayaan Psikologis adalah 0,942 dengan keterangan reliabel, dan Counterproductive Work Behavior adalah 0,987 dengan keterangan reliabel. Hasil uji reliabilitas yang disajikan dalam uji ini syarat minimum suatu kuesioner untuk memenuhi reliabilitas adalah jika nilai cronbach's alpha bernilai $\geq 0,6$. Jadi untuk nilai Cronbach's Alpha di masing-masing variabel telah melebihi 0,6 ini berarti hasil dari data kuesioner dinyatakan reliable. 
Uji asumsi klasik dilakukan untuk menguji kelayakan model yang dibuat sebelum digunakan untuk memprediksi, adapun uji asumsi klasik meliputi: uji normalitas, uji multikolinearitas dan uji heteroskedastisitas. Uji normalitas akan menunjukan hasil yang didapatkan dengan menggunakan uji KolmogorovSmirnov dengan signifikansi lebih besar dari 0,05 yaitu 0,073 maka dapat disimpulkan bahwa model regresi terdistribusi secara normal. Berdasarkan hasil pengujian multikolinearitas dapat diperoleh hasil keadilan organisasional sebasar 0,730 dengan VIF 2.701, sedangkan untuk pemberdayaan psikologis sebesar 0,370 dengan VIF 2.701. jadi dapat diketahui nilai VIF (Varian Inflatation Factor) tidak lebih dari 10 dan mempunyai angka tolerance tidak kurang dari 0,1, maka ini berarti dalam model regresi tidak terjadi multikolinearitas. Berdasarkan hasil pengujian heteroskedastisitas dapat diperoleh hasil $\mathrm{T}$ dari keadilan organisasional sebasar 0,579 dengan sig 0,564, sedangkan untuk pemberdayaan psikologis untuk nilat $\mathrm{t}$ adalah $-1,869$ dengan sig 0,064. Jadi dapat dilihat bahwa variabel Keadilan Organisasional memiliki nilai sig. $0,564>0,05$, variabel Pemberdayaan Psikologis memiliki nilai sig. 0,064>0,05, ini berarti pada model regresi tidak terjadi gejala heteroskedastisitas. Pengujian ini dilakukan untuk mengetahui tingkat signifikansi pengaruh variabel bebas secara bersama (simultan) terhadap variabel terikat.

Uji F dilakukan dengan membandingkan nilai Fhitung dengan nilai Ftabel pada taraf signifikansi 0,05. Jadi dapat diketahui bahwa Fhitung $=59.678$ dan nilai Ftabel dengan tingkat keyakinan 95\% dan $\alpha=0,05$; df $=(2,107)$ adalah sebesar 3.081. Oleh karena Fhitung (59.678) lebih besar dari Ftabel $(2,70)$ dengan nilai $\mathrm{p}<0,05$ maka dapat disimpulkan bahwa keadilan organisasional dan pemberdayaan psikologis secara simultan berpengaruh terhadap counterproductive work behavior. Hal ini berarti model dapat digunakan untuk analisa lebih lanjut atau dengan kata lain model dapat digunakan untuk mempresentasikan, karena hasil goodness of fit-nya baik. Pengaruh tiap-tiap variabel bebas dalam model ini digunakan untuk mengetahui pengaruh variabel bebas, yaitu keadilan organisasional, dan pemberdayaan psikologis secara parsial terhadap counterproductive work behavior.

Uji t dilakukan dengan membandingkan nilai thitung dengan ttabel pada taraf signifikansi 0,05 dengan pengujian $\alpha=0,05$, df $=(2,107)$, sehingga ttabel $(0,05: 2,107)$ adalah sebesar 1.659 . Jadi berikut ini merupakan hasil uji dari $t$ hitung pada variabel keadilan organisasional dan pemberdayaan psikologis: pengujian t hitung pada variabel keadilan organisasional, hipotesis ini menyatakan bahwa keadilan organisasional berpengaruh terhadap counterproductive work behavior. nilai signifikan keadilan organisasional lebih kecil dari 0,05 maka $\mathrm{H} 0$ diterima dan nilai thitung $=-3.680$ lebih kecil dari ttabel $=1.659$ maka $\mathrm{H} 0$ diterima, ini berarti keadilan organisasional berpengaruh positif terhadap counterproductive work behavior karyawan di Hotel Mercure Sanur. Positif, erat, dan signifikan dalam arti kedua variabel antara keadilan organisasional dan counterproductive work behavior saling berpengaruh besar/erat satu sama lain dengan didasarkan pada perhitungan olah data statistik yang signifikan. Pengujian t hitung pada variabel pemberdayaan psikologis, hipotesis ini menyatakan bahwa pemberdayaan psikologis berpengaruh terhadap counterproductive work behavior. 
Hasil analisis uji t menunjukkan nilai signifikan pemberdayaan psikologis lebih kecil dari 0,05 maka $\mathrm{H} 0$ diterima dan nilai thitung $=-3.339$ lebih kecil dari ttabel $=1.659$ maka H0 diterima, ini berarti pemberdayaan psikologis berpengaruh signifikan positif terhadap counterproductive work behavior karyawan di Hotel Mercure Sanur. Positif, erat, dan signifikan dalam arti kedua variabel antara pemberdayaan psikologis dan counterproductive work behavior karyawan di Hotel Mercure Sanur saling berpengaruh besar/erat satu sama lain dengan didasarkan pada perhitungan olah data statistic yang signifikan.

Hasil analisis data penelitian berdasarkan metode analisis faktor konfirmatori melaporkan bahwa validitas pengukuran data yang ditunjukan oleh parameter variance explained variabel sebagai berikut: nilai keadilan organisasional adalah 166.924, pemberdayaan psikologis adalah 73.403, dan counterproductive work behavior adalah 233.826. Besaran reliabilitas data dari variabel keadilan organisasional, pemberdayaan psikologis, dan counterproductive work behavior juga menunjukan bahwa kualitas data cukup memuaskan yang ditunjukan oleh nilai besaran Alpha Cronbach untuk variabel keadilan organisasional sebesar 0,963, variabel pemberdayaan psikologis 0,942, dan untuk variabel counterproductive work behavior 0,987 . Validitas data intensi menunjukan besaran validitas yang memuaskan ditunjukan pada nilai total variance explained sebesar 0,64 Alpha Cronbach bernilai 0,987. Pengujian hipotesis penelitian dilakukan dengan metode regresi linier berganda yang menunjukan bahwa pengaruh keadilan organisasional secara signifikan berkorelasi positif terhadap counterproductive work behavior $(\mathrm{B}=0,445, \mathrm{t}=$ $3.680, p=0,121)$. Korelasi antara pengaruh pemberdayaan psikologis terhadap counterproductive work behavior ditunjukan secara statistik positif signifikan (B $=0,603, \mathrm{t}=3.339, \mathrm{p}=0,181$ ).

Beberapa keterbatasan dalam penelitian yang dapat ditarik dari penelitian ini adalah penelitian ini hanya menguji pengaruh keadilan organisasional, dan pemberdayaan psikologis terhadap counterproductive work behavior di Hotel Mercure Sanur. Saran untuk penelitian selanjutnya dapat memakai variabel job stress, incivility, leader exchange, the impact of pesonality and team context. Jumlah sampel yang digunakan terbatas, yakni sebesar 110 responden dari 214 karyawan dan sampel yang diperbolehkan diambil hanya untuk karyawan biasa dan supervisor di Hotel Mercure Sanur. Saran untuk penelitian selanjutnya perlu di konsistensikan dari hasil temuan agar perlu diuji lagi pada konteks karyawan manajerial, khususnya karyawan yang memiliki jabatan manajer dan asisten manajer. Belum dimasukkan variabel-variabel pendukung lainnya seperti: organizational citizenship behavior, kepempimpinan etis, kepuasan kerja, komitmen organisasi, mediasi antara beban kerja dan job relation.

\section{SIMPULAN}

Simpulan dari penelitian ini berdasarkan pada pembahasan sebelumnya, adalah Keadilan organisasional berpengaruh positif dan signifikan terhadap counterproductive work behavior karyawan di Hotel Mercure Sanur. 
Pemberdayaan Psikologis berpengaruh positif dan signifikan terhadap counterproductive work behavior karyawan di Hotel Mercure Sanur.

Saran dari penelitian ini berdasarkan kesimpulan di atas yang dapat diberikan kepada pihak yang memerlukan adalah Hotel Mercure Sanur diharapkan kedepannya dapat memberikan kesempatan kepada setiap karyawannya untuk bebas memberi masukan pendapat tentang bagaimana karyawan seharusnya melakukan pekerjaan, sehingga karyawan di Hotel Mercure Sanur bisa merasa lebih fleksibel dan di hargai pada saat bekerja. Hotel Mercure Sanur diharapkan bisa menjaga hubungan yang baik dengan setiap karyawannya, karena hal ini selain dapat membuat citra yang baik di mata karyawan. Karyawan juga akan merasa lebih diperhatikan dan dihargai keberadaanya, sehingga diharapkan nantinya hal ini dapat meredam timbulnya counterproductive work behavior karyawan di Hotel Mercure Sanur. Peneliti selanjutnya dimasa mendatang hendaknya memperhatikan dan mengembangkan faktor-faktor lain yang dapat mempengaruhi counterproductive work behavior selain dari keadilan orgaisasional, dan pemberdayaan psikologis agar kedepannya perusahaan apapun dapat mempertahankan kualitas sumber daya manusianya serta mampu memberikan hasil yang terbaik bagi perusahaan.

\section{REFERENSI}

Adams, J. S. (1965). Inequity In Social Exchange. Advances in Experimental Social Psychology. https://doi.org/10.1016/S0065-2601(08)60108-2

Ahmed, S., \& Uddin, M. N. (2012). Job satisfaction of bankers and its impact in banking: A case study of Janata Bank. ASA University Review, 6(2), 95-102.

Al-Zu'bi, H. A. (2010). A Study of Relationship between Organizational Justice and Job Satisfaction. International Journal of Business and Management. https://doi.org/10.5539/ijbm.v5n12p102

Al Musadieq, M., Rimawan, E., Mulyanto, A. D., \& Mahendra, A. S. (2016). PENGARUH PEMBERDAYAAN PSIKOLOGIS TERHADAP EFIKASI DIRI DAN KECERDASAN EMOSIONAL. SINERGI. https://doi.org/10.22441/sinergi.2016.3.004

Ambrose, M., \& Arnaud, A. (2005). Are procedural justice and distributive justice conceptually distinct? In Handbook of organizational justice. https://doi.org/http://dx.doi.org/10.4324/9780203774847

Ambrose, M. L., Seabright, M. A., \& Schminke, M. (2002). Sabotage in the workplace: The role of organizational injustice. Organizational Behavior and Human Decision Processes. https://doi.org/10.1016/S0749-5978(02)00037-7

Anindyajati, M., \& Karima, C. M. (2004). Peran Harga Diri Terhadap Asertivitas Remaja Penyalahguna Narkoba (Penelitian Pada Remaja Penyalahguna Narkoba di Tempat-Tempat Rehabilitasi Penyalahguna Narkoba). Jurnal 


\section{Psikologi.}

Appelbaum, S. H., Deguire, K. J., \& Lay, M. (2005). The relationship of ethical climate to deviant workplace behaviour. In Corporate Governance. https://doi.org/10.1108/14720700510616587

Aris, N., Fazlika, J., Kasbawati, Jusmawati, \& Erawaty, N. (2017). The existence of global attractor in the lorenz system. Far East Journal of Mathematical Sciences. https://doi.org/10.17654/MS102051045

Astuti, Evi Mega; Hasiholan, Leonardo Budi; Fathoni, A. (2019). The Effect Of Empowerment Of Psychology, Employment Ability, And Motivation On Employee Performance In Bpr Mitrapersada Mranggen In Mranggen Branch In Mediation Commitment To Employee. Journal of Management.

Boddy, C. R. (2014). Corporate Psychopaths, Conflict, Employee Affective WellBeing and Counterproductive Work Behaviour. Journal of Business Ethics. https://doi.org/10.1007/s10551-013-1688-0

Brief, A. P., \& Weiss, H. M. (2002). Organizational Behavior: Affect in the Workplace. Annual Review of Psychology, 53(1), 279-307. https://doi.org/10.1146/annurev.psych.53.100901.135156

Cascio, W. F. (2010). Managing Human Resources: Productivity, Quality of Work Life, Profits. Work.

Chernyak-Hai, L., \& Tziner, A. (2014). Relationships between counterproductive work behavior, perceived justice and climate, occupational status, and leadermember exchange. Revista de Psicologia Del Trabajo y de Las Organizaciones. https://doi.org/10.5093/tr2014a1

Choi, J. Y., Miao, C., Oh, I. S., Berry, C. M., \& Kim, K. (2019). Relative Importance of Major Job Performance Dimensions in Determining Supervisors' Overall Job Performance Ratings. Canadian Journal of Administrative Sciences. https://doi.org/10.1002/cjas.1495

Colquitt, J. A., Conlon, D. E., Wesson, M. J., Porter, C. O. L. H., \& Ng, K. Y. (2001). Justice at the millenium: A meta-analytic review of 25 years of organizational justice research. Journal of Applied Psychology. https://doi.org/10.1037//0021-9010.86.3.425

Conger, J. A., \& Kanungo, R. N. (1988). The Empowerment Process: Integrating Theory and Practice. Academy of Management Review. https://doi.org/10.5465/amr.1988.4306983

Cropanzano, R., Bowen, D. E., \& Gilliland, S. W. (2007). The management of organizational justice. In Academy of Management Perspectives. https://doi.org/10.5465/AMP.2007.27895338 
Dalal, R. S. (2005). A meta-analysis of the relationship between organizational citizenship behavior and counterproductive work behavior. In Journal of Applied Psychology. https://doi.org/10.1037/0021-9010.90.6.1241

Fox, S., Spector, P. E., \& Miles, D. (2001). Counterproductive work behavior (CWB) in response to job stressors and organizational justice: Some mediator and moderator tests for autonomy and emotions. Journal of Vocational Behavior. https://doi.org/10.1006/jvbe.2001.1803

Gibson, J. L., Ivancevich, J. M., Donelly Jr, J. H., \& Konopaske, R. (2012). Organizations Behaviour, Structure, Processes. In The McGrawHill companies.

Ibrahim, N., Ismail, A., Mohamed, N. K., Salim, S. S., \& Yusuf, M. H. (2015). Effect of Psychological Empowerment and Transformational Leadership on Organizational Commitment. Makara Human Behavior Studies in Asia. https://doi.org/10.7454/mssh.v19i2.3476

Kelloway, E. K., Francis, L., Prosser, M., \& Cameron, J. E. (2010). Counterproductive work behavior as protest. Human Resource Management Review. https://doi.org/10.1016/j.hrmr.2009.03.014

Kristanto, S., Rahyuda, I. K., \& Riana, I. G. (2014). Pengaruh Keadilan Organisasional Terhadap Kepuasan Kerja Dan Dampaknya Terhadap Komitmen, Dan Intensi Keluar di PT Indonesia Power UPB Bali. E-Jurnal Ekonomi Dan Bisnis Universitas Udayana.

Lewis, R. P. (2013). Keadilan Distributif, Keadilan Prosedural, Keadilan Interaksional Kompensasi Dan Komitmen Karyawan. JRMB. https://doi.org/10.1001/jamaophthalmol.2016.3625

Luth, M. T. (2013). The bright and dark sides of empowerment: Linking psychological empowerment and job stressors to proactive and counterproductive work behaviors. Dissertation Abstracts International Section A: Humanities and Social Sciences.

Marcus, B., Taylor, O. A., Hastings, S. E., Sturm, A., \& Weigelt, O. (2016). The Structure of Counterproductive Work Behavior. Journal of Management. https://doi.org/10.1177/0149206313503019

Norwood, J. M. (2019). Psychological uncertainty, stress, frustration, and their relationship with counterproductive workplace behavior. In Dissertation Abstracts International: Section B: The Sciences and Engineering.

Nugraheni, H., \& Wahyuni, S. (2017). PENGARUH NARSISME DAN JOB STRESSOR PADA PERILAKU KERJA KONTRA PRODUKTIF DENGAN RESPON EMOSIONAL NEGATIF (ANGER) SEBAGAI 
MEDIATOR. Jurnal Bisnis Dan Manajemen. https://doi.org/10.20961/jbm.v16i2.4090

Perkins, D. D., \& Zimmerman, M. A. (1995). Empowerment theory, research, and application. American Journal of Community Psychology. https://doi.org/10.1007/BF02506982

Permatasari, M. (2012). PENGARUH GAYA BERPIKIR, INTEGRITAS DAN USIA PADA PERILAKU KERJA YANG KONTRAPRODUKTIF. Jurnal Psikologi Ulayat. https://doi.org/10.24854/jpu12012-11

Pfeffer, J., Cialdini, R. B., Hanna, B., \& Knopoff, K. (1998). Faith in supervision and the self-enhancement bias: Two psychological reasons why managers don't empower workers. Basic and Applied Social Psychology. https://doi.org/10.1207/s15324834basp2004_8

Prameswari, K., \& Suwandana, G. (2017). PENGARUH KEADILAN ORGANISASIONAL, KOMITMEN ORGANISASIONAL, DAN KEPUASAN KERJA TERHADAP ORGANIZATIONAL CITIZENSHIP BEHAVIOR. E-Jurnal Manajemen Universitas Udayana.

Pujadi, A. (2007). FAKTOR-FAKTOR YANG MEMPENGARUHI MOTIVASI BELAJAR MAHASISWA: STUDI KASUS PADA FAKULTAS EKONOMI UNIVERSITAS BUNDA MULIA. Business Management Journal. https://doi.org/10.30813/bmj.v3i2.338

Rafiee, M., Hoveida, R., \& Rajaeipoor, S. (2015). The Relationship of the Deviant Workplace Behavior with the Organizational Justice and Staff Development in the Universities of Tehran. International Journal of Human Resource Studies. https://doi.org/10.5296/ijhrs.v5i1.7075

Reisel, W., Probst, T., Chia, S. L., Maloles, C., \& König, C. (2010). The effects of job insecurity on job satisfaction, organizational citizenship behavior, deviant behavior, and negative emotions of employees. International Studies of Management and Organization. https://doi.org/10.2753/IMO00208825400105

Robbins, S. P., \& Judge, T. A. (2008). Perilaku organisasi edisi ke-12. In Chemical and Petroleum Engineering.

Robinson, S. L., \& Bennett, R. J. (1995). A Typology of Deviant Workplace Behaviors: A Multidimensional Scaling Study. Academy of Management Journal. https://doi.org/10.5465/256693

Rotundo, M., \& Sackett, P. R. (2002). The relative importance of task, citizenship, and counterproductive performance to global ratings of job performance: A policy-capturing approach. Journal of Applied Psychology. 
https://doi.org/10.1037//0021-9010.87.1.66

Rusdi, Z. M. (2015). Analisis komparatif perilaku kerja kontra produktif pada instansi pemerintah dan instansi swasta di Bandarlampung. Jurnal Sains Manajemen. https://doi.org/10.1017/CBO9781107415324.004

Saltzstein, A. L., Ting, Y., \& Saltzstein, G. H. (2001). Work-Family Balance and Job Satisfaction: The Impact of Family-Friendly Policies on Attitudes of Federal Government Employees. Public Administration Review. https://doi.org/10.1111/0033-3352.00049

Spector, P. E., Fox, S., Penney, L. M., Bruursema, K., Goh, A., \& Kessler, S. (2006). The dimensionality of counterproductivity: Are all counterproductive behaviors created equal? Journal of Vocational Behavior. https://doi.org/10.1016/j.jvb.2005.10.005

Spreitzer, G. M. (1995). An empirical test of a comprehensive model of intrapersonal empowerment in the workplace. American Journal of Community Psychology. https://doi.org/10.1007/BF02506984

STEPHANUS JOSEP, E. (2017). Pengaruh Dimensi Keadilan Organisasional terhadap Perilaku Kerja Kontraproduktif Karyawan (Studi pada Divisi ATKMart PT. Gading Murni Surabaya). Jurnal Ilmu Manajemen (JIM).

Sugiyono. (2013). Metode Penelitian Pendidikan Pendekatan Kuantitaif, Kualitatif, dan R\&DSugiyono. 2013. "Metode Penelitian Pendidikan Pendekatan Kuantitaif, Kualitatif, dan R\&D." Metode Penelitian Pendidikan Pendekatan Kuantitaif, Kualitatif, dan R\&D. https://doi.org/10.1. In Metode Penelitian Pendidikan Pendekatan Kuantitaif, Kualitatif, dan R\&D. https://doi.org/10.1007/s13398-014-0173-7.2

Susilawati, I. R. (2018). Perilaku Kerja Produktif dan Kontra Produktif: Sebuah Studi Meta-analisis. Mediapsi. https://doi.org/10.21776/ub.mps.2018.004.01.2

Usmani, S., \& Jamal, S. (2013). Impact of distributive justice, procedural justice, interactional justice, temporal justice, spatial justice on job satisfaction of banking employees. Review of Integrative Business and Economics Research.

Wilkerson, J. M., Evans, W. R., \& Davis, W. D. (2008). A test of coworkers' influence on organizational cynicism, badmouthing, and organizational citizenship behavior. Journal of Applied Social Psychology. https://doi.org/10.1111/j.1559-1816.2008.00391.x

Wiratama, W. J., \& Rahyuda, A. G. (2017). KEPEMIMPINAN ETIS TERHADAP COUNTERPRODUCTIVE WORK BEHAVIOUR PADA HOTEL 
E-Jurnal Manajemen, Vol. 9, No. 6, 2020 : 2288-2307

DISCOVERY KARTIKA PLAZA KUTA Fakultas Ekonomi dan Bisnis Universitas Udayana ( Unud), Bali, Indonesia Banyaknya hotel di Bali mengakibatkan persaingan bisnis hotel kian sengit . Hal . 5, 2133-2160.

Wiwiek, W., \& Sondakh, O. (2015). Pengaruh keadilan organisasional pada motivasi karyawan dan komitmen organisasional. Jurnal Siasat Bisnis. https://doi.org/10.20885/jsb.vol19.iss1.art6 